\title{
Emoções e sentimentos no processo de aprendizagem: um estudo de caso
}

\author{
Denise de Camargo \\ Universidade Federal do Paraná
}

\begin{abstract}
Resumo
Este trabalho apresenta o estudo de caso de uma jovem com histórico de dificuldades de aprendizagem. Buscou-se, na narrativa registrada nos relatórios de cinco anos de sessões em terapia numa Clínica Escola, analisar os núcleos de significação de reconstrução da identidade que a jovem fez na sua história de vida. A análise e sua interpretação mostraram que a essência da identidade de Mara foi constituída através dos significados atribuídos nas inter-relações com as pessoas mediadoras de suas atividades. A narrativa das emoções e sentimentos vividos e expressos é indicadora e constitutiva da identidade singular de Mara, entremeada por dificuldades e condições desfavoráveis para a aprendizagem. O caso demonstra que as limitações mediadas pelos fatores sociais e psicológicos foram decisivas para a história do seu desenvolvimento cultural.

Palavras-chave: dificuldade de aprendizagem; emoção; sentimento; identidade; perspectiva históricocultural.
\end{abstract}

\begin{abstract}
The emotions and feelings in the learning process: a study of case

The article presents a young woman's case that shows a history of learning disabilities. The author searched in the narrative registered in the reports of five years of therapy sessions in a clinical school in order to analyze the meanings of reconstruction of the identity that the young woman made in her lifespan. The analysis and its interpretation showed that the essence of Mara's identity was constituted by the meanings attributed to the inter-relations with those who mediated her activities. The narrative of the emotions and feelings lived and expressed is indicative and constituent of the singular identity of Mara, with disabilities and unfavorable conditions of learning. The case demonstrates that the limitations mediated by the social and psychological factors determined the story of Mara's cultural development.

Keywords: learning disabilities; emotions; feelings; identity; historical-cultural perspective.
\end{abstract}

\section{INTRODUÇÃO}

Estudos recentes (Smith, 2001; Grégoire, 2000; Trapani \& Gettinger, 1999; Anastopoulos, 1999; García, 1998; Marchesi \& Martín, 1995; Rourke, 1985) avançam na compreensão de que múltiplos fatores contribuem para a causa e o desenvolvimento das dificuldades de aprendizagem.

Também as pesquisas na área da neuropsicologia (Rourke, 1985; Grégoire, 2000), envolvendo avaliações abrangentes, apontam as áreas básicas que interferem no processamento adequado de informações: atenção, coordenação motora, percepção visual, memória, formação de conceitos, processamento da linguagem. $\mathrm{Na}$ abordagem da neuropsicologia, a identificação das áreas que apresentam déficits é o pré-requisito fundamental para o estabelecimento do planejamento da intervenção terapêutica. Essa informação é essencial para a avaliação do programa e o estabelecimento dos objetivos e estratégias para minimização das deficiências e maximização das habilidades que estão preservadas.
No debate sobre as falhas da educação, muitas análises têm sido feitas sobre o porquê de alguns alunos aprenderem, enquanto outros se mostram incapazes (Coll, Palácios \& Marchesi, 1995; Souza Patto, 1989). Várias soluções têm sido propostas. Currículos têm sido modificados para irem ao encontro das necessidades da sociedade tecnológica moderna. A falha da formação, hoje, é reconhecida como problema social, desde que se tornou evidente que as crianças pertencentes a famílias de baixa renda constituem um número proporcionalmente grande entre os que fracassam na escola. Estudos e questões importantes têm surgido destes debates, principalmente na área da linguagem e nos estudos sobre prática discursiva na sala de aula (Smolka, 1991).

$\mathrm{Na}$ área da psicopedagogia, os trabalhos sobre as dificuldades de aprendizagem (Scoz, Rubinstein, Rossa \& Barone, 1987) têm procurado chegar a diagnósticos precisos das causas e deficiências apresentadas pelas crianças. A avaliação recai principalmente sobre 
o "potencial intelectual" e as diversas habilidades, tais como: fala, leitura, escrita, aritmética e as habilidades metacognitivas. O diagnóstico é centrado principalmente no aspecto cognitivo.

Contribuindo para abordar este problema, o estudo de caso aqui apresentado aponta o estreito vínculo entre a construção da identidade, a emoção e a constituição da pessoa diagnosticada com "dificuldades", "distúrbios" ou "problemas de aprendizagem" Pretende-se, com este trabalho, mostrar como a emoção está presente nas dificuldades de aprendizagem, e exemplificar, por meio deste estudo de caso, a sua dinâmica. A análise centra-se na narrativa da construção da identidade ${ }^{2}$, concebida aqui como processo histórico implicado nas relações sociais afetivas e nas experiências reais vividas no mundo.

O foco de análise é colocado nas emoções/sentimentos $^{3}$ e na construção da identidade a partir da narrativa da paciente. Para a interpretação dos núcleos de significado ${ }^{4}$, o material utilizado foi recolhido em entrevista aberta $^{5}$ e a partir dos resumos de relatórios resultantes de cinco anos de sessões de terapia. Os dados da entrevista sobre sua história na escola foram transcritos e submetidos à análise gráfica ${ }^{6}$ que possibilitou marcar os núcleos de significado para proceder à análise das emoções articuladas às representações expressas sobre si mesma.

Nesses cinco anos sob supervisão de uma professora clínica, a paciente passou por cinco estagiárias do quinto ano do curso de psicologia. Deu-se a ela o nome fictício de Mara, visando a preservar seu anonimato.

Quando iniciou o atendimento na Clínica Escola, Mara tinha 23 anos, morava com seus pais e uma irmã e pertencia a uma família que pode ser classificada como sendo de classe média baixa. Mara tinha concluído o primeiro grau. Entrou no primeiro ano da escola aos sete anos de idade, reprovada na primeira série, na segunda, na quarta, na quinta, duas vezes na sexta série e na sétima série do primeiro grau. Após a oitava série ficou três anos sem estudar. Nos três primeiros anos de terapia não estava estudando ou trabalhando. Apresentava dificuldades na fala, trocando letras e emitindo sons nasais. A estagiária anota no prontuário que Mara teve anoxia no parto, possui a voz anasalada, mostra alguma incoordenação motora, troca alguns fonemas, tem certa dificuldade de aprendizagem.

Na primeira entrevista Mara conta que a mãe demorou a ir para o hospital quando ela estava nascendo, o que atrasou o parto. Após algumas entrevistas, a hipótese diagnóstica elaborada foi a seguinte: "A paciente apresenta algum atraso em seu desenvolvimento, superproteção familiar, o que nos sugere algum grau de comprometimento intelectual. Possui alguma autocrítica com sentimentos de desamparo, revelando auto-estima rebaixada, e manifestou problemas fonoaudiológicos".

\section{OS NÚCLEOS DE SIGNIFICADO E A CONSTRUÇÃO DA IDENTIDADE}

Primeiramente retomou-se a narrativa de Mara sobre aspectos de sua história, pontuaram-se os núcleos de significado que surgiram ao longo dos seus relatos e procedeu-se à análise e interpretação destes significados.

\subsection{Relações Familiares Conflituosas}

A hipótese diagnóstica decorreu de relatos em entrevista, quando Mara chegou dizendo ter muito medo, solidão e depressão. Relatava que se sentia inferior e muito solitária, que todos os seus familiares trabalhavam fora, e ela queria desabafar, queria ajuda, queria ouvir alguém dizer: "Vamos lá, Mara". Citando uma de suas falas: "Queria me descobrir (...) me valorizar”.

Com o objetivo de conhecer mais sobre o seu desenvolvimento, pediu-se o comparecimento dos pais para uma entrevista. Veio sua irmã, que informou: " $O$ problema de Mara é que ela passou da hora de nascer. Mara estava com o cordão enrolado no pescoço. O médico explicou que ela sobreviveria, mas era um caso raro. Ficaria deficiente".

Mara conta que sabia desse fato por uma pessoa próxima da família, que disse a ela: "Você passou da hora de nascer, faltou-lhe oxigênio no cérebro". Afirma que gostaria de falar mais francamente com seus pais sobre o fato de ser, segundo ela, retardada. Gostaria de saber a verdade, mas não pergunta porque tem medo de magoá-los.

Diz que quando pergunta a seus pais sobre o seu problema na cabeça, eles dizem para "não pôr chifre em cabeça de cavalo".

Sobre o fato de não tratar do assunto com Mara, a irmã responde: "Até hoje nunca contamos a Mara qual é seu problema, pois uma vez um psicólogo orientou-nos para não contar. Ela só poderia trabalhar com alguém conhecido, devido ao seu problema”.

Em entrevista com a mãe, o relato foi o seguinte: "O problema de Mara é que faltou-lhe oxigênio no cérebro. Ela não tem coordenação motora, as letras ficam muito grandes ou pequenas. (...) sempre foi muito preguiçosa, não gosta do serviço de casa”.

Mara confessa que não sabe o porquê, mas sente muito medo de sua mãe: "Sinto mais medo que respeito". Fala que antes era mais forte, agora não participa, não discute, não quer apanhar. "Minha família não é democrática. Minha mãe que decide, é dona da verdade. Não participo, não discuto, fico quieta”. 
Ainda neste relato, ela diz: "A primeira vez que eu me vesti como moça, a minha mãe me chamou de prostituta". (...) "Acho que minha mãe não gosta de mim. Acho que ela tem um sentimento de culpa".

Conta que, quando pequena, apanhou de uma colega, e sua mãe foi conversar com a mãe da menina, e disse a ela que Mara era doente mental, que tinha problema na cabeça. Mara ouviu. Sua mãe, depois, disse a ela para não ligar, que só havia dito aquilo para que a menina não batesse mais nela. "Onde tem fumaça tem fogo", comentou Mara ao terminar o relato.

A identidade de retardada pressuposta pelo médico é reposta em vários momentos, ao que explica Ciampa: "Uma vez que a identidade pressuposta é reposta, ela é vista como dada e não como se dando num contínuo processo de identificação. É como se uma vez identificada a pessoa, a produção de sua identidade se esgotasse com o produto" (Ciampa, 1986, p. 66).

\subsection{Profecia sobre o trabalho}

Em um dos relatos, Mara diz estar procurando emprego, mas que não consegue. Acha que existe muita discriminação e que, se fosse mais bonita, conseguiria.

A irmã se expressa: "Hoje Mara tem a mentalidade mais ou menos entre 13 e 15 anos. Sai de casa sozinha apenas a partir de dois anos para cá. Procurou emprego, porém não consegue entrar em nenhum, pois na entrevista médica e psicológica não passa".

Os significados expressos pela irmã e, antes, pela mãe estão presentes nas interações de Mara com outras pessoas. Estes significados ocupam um lugar de poder nas relações de Mara com o mundo. Na fala da irmã transparece o poder do discurso dos especialistas reproduzido como profecia auto-realizadora (Rosenthal \& Jacobson, 1989), como poder distribuído através dos discursos de especialistas, que funcionam como uma forma de controlar os indivíduos e marcar sua posição na sociedade (Foucault, 1979).

\subsection{Suas lembranças sobre a escola, mediadas pelas lembranças de sua irmã e sua mãe}

Mara afirma que foi reprovada na escola diversas vezes. Ao final do primeiro grau, os professores fizeram uma reunião com seus pais e trancaram sua matrícula, justificando que ela não teria condições de continuar os estudos. Mara diz que ser professora era um sonho, e a possibilidade de não realizá-lo foi uma decepção.

Segundo a irmã, "o fato de terem trancado a matrícula de Mara na escola seria devido à postura do médico, que recomendou que ela não forçasse o cérebro".
Mara relata: "A professora começou a me chamar de retardada, que meu lugar não era lá...". "Ela falava que quando eu ia comer sorvete, em vez de eu lamber o sorvete, o sorvete que ia lamber minha testa."

Ela pergunta se é louca e se seu cérebro é realmente "um pouco maior que o de um papagaio, como o neurologista falou". "Quero saber das minhas capacidades e limitações". "Todos me tratam como retardada". Diz ainda: "O que mais me incomoda é o fato de não saber se sou retardada".

Mara lembra: "Eu não gostava de falar inglês, os colegas riam muito de mim... Sempre teve algumas diferenças entre eu e os meus colegas do primário e do ginásio, as crianças riam de mim e eu não entendia muito por que... na época eu não era tão humilhada porque eu não tinha consciência do que eles riam, do que eles gozavam de mim, da minha voz, gozavam do jeito de rir".

Ela descreve um período de sua vida que considera especialmente difícil. Afirma que tentava conversar com a mãe sobre a diferença que sentia entre ela e as outras crianças, mas a mãe dizia que isso tudo era fantasia. Ouviu uma das irmãs dizendo que não gostava dela, um irmão chamando-a de mimada e outro de retardada. Com 11 anos, apanhou de uma colega que tinha ciúmes da professora. Aos 15 anos, brigou com uma colega, e a turma toda "virou a cara" para ela. Aos 17 anos, durante uma prova, o lápis de uma colega caiu, ela foi avisar, e a professora brigou com ela dizendo que ali não era sala de criança retardada.

Num contexto como o relatado por Mara, fica evidente como a concepção homogeneizadora presente na sociedade e na escola, que reflete a reprodução do discurso dos especialistas, determina as relações intersubjetivas entre os alunos e as relações dos professores para com os alunos. Concepção ainda dominante na psicologia educacional, fundamentada na psicologia do desenvolvimento, que considera que as salas de aula devem ser compostas por alunos da mesma etapa, período ou fase de desenvolvimento. A análise permite constatar o caráter discriminador e excludente desse discurso, que não suporta a diferença, a diversidade cultural, o pluralismo cultural e a heterogeneidade entre os alunos. Nesse contexto escolar, a identidade posta e reposta a Mara encontra um terreno propício para sua reafirmação; não há espaço para a negação desta identidade, posta justamente pelo autoritarismo homogeneizador da instituição escolar (Kleiman, 2001).

\subsection{Disfunções neurológicas a serem conhecidas e compreendidas}

Após o histórico trazido pela irmã em relação ao parto, solicitou-se uma avaliação neurológica. Mara passou a ter uma grande expectativa em relação ao 
resultado deste exame. A avaliação foi marcada para seis meses depois, em um hospital beneficente. Ela expressa sua expectativa em todas as sessões seguintes: "Quero saber das minhas capacidades e limitações". "Todos me tratam como retardada." “...o que mais me incomoda é o fato de não saber se sou retardada. Na casa de minha irmã disseram que eu era retardada e como poderia escrever cartões de Natal."

Depois de algumas sessões, Mara inicia o encontro dizendo: "Eu fico superansiosa, quero que acabe tudo isso logo". Quando a estagiária lhe pergunta o que ela quer que acabe, Mara afirma que sua irmã pegou o resultado dos exames neurológicos no hospital e entregou-o à fonoaudióloga, pedindo para não devolvêlo a ela. Passa, então, a falar que a família sempre resolve as coisas por ela. "Minha mãe sempre foi uma mulher muito exigente. Os filhos têm que dar satisfações para ela. O que ela diz é lei.” “...aos berros ou com chantagem emocional. Comigo ela sabe apertar o calo. Ela exige que eu seja uma pessoa normal".

Ainda nesta sessão, fala que pegou os resultados dos exames neurológicos ${ }^{7}$ com a fonoaudióloga: "Quando eu peguei aqueles papéis parecia que era um troféu. Depois eu vi que eram só papéis. Eu tô cansada de saber o que tem naqueles papéis. Por que tô tão preocupada com isso?".

\subsection{Relações afetivas/amorosas}

Em uma das sessões, Mara comenta que contou a uma amiga da família que "tinha um namoradinho" e esta senhora disse-lhe que ela não poderia estar namorando se tinha um problema na cabeça. Mara respondeu-lhe que o namorado gostava dela mesmo assim: "Não ia dar o gostinho para ela de me ver chorar".

$\mathrm{O}$ estigma de retardada foi colocado no momento do nascimento, é repetido pelo relato da irmã e da mãe e recolocado pela própria Mara quando recorda o que a vizinha, a professora, o neurologista falaram sobre ela.

É importante reproduzir, aqui, a fala da mãe, relatada por Mara: "A primeira vez que eu me vesti como moça, a minha mãe me chamou de prostituta”. Assim, os significados expressos na fala da vizinha e da mãe reafirmam que a identidade de mulher também é negada a ela.

\subsection{O olhar sobre si mesma}

Mara fala sobre si mesma: "Eu sou cômoda, não vou à luta, não quebro barreiras, sou muito medrosa. Não acho os porquês, se estão dentro de mim...".

Diz sentir-se "deslocada, aérea": "Fico olhando as pessoas na Rua XV e fico pensando como deve ser uma pessoa normal, livre, correndo de um lado para outro com trabalho, estudo. Olho minha irmã passan- do batom, pondo brincos e fico pensando como deve ser esta sensação. Era o que eu mais queria".

Parece sentir-se sempre inferior. Afirma que não quer ser mais que os outros, quer ser igual. Diz que sempre foi perdedora, nunca ganhadora.

Segundo Ciampa:

...a expectativa generalizada de que alguém deve agir de acordo com o que é (e conseqüentemente ser tratado como tal). De certa forma, re-atualizamos através de rituais sociais uma identidade pressuposta que assim é reposta como algo já dado, retirando em consequiência o seu caráter de historicidade, aproximando-a mais da noção de um mito que prescreve as condutas corretas, reproduzindo o social (Ciampa, 1986, p. 66).

\section{Significados emergem na fala de Mara}

Os significados encontrados a partir da análise e interpretação da entrevista aberta sobre sua história na escola podem ser divididos em dois momentos, segundo os núcleos de significação encontrados. O primeiro, comentado neste item, compreende o início de sua escolaridade até a oitava série. Como já foi dito, Mara ficou três anos sem estudar e depois retornou à escola para fazer o segundo grau. O segundo momento, discutido mais à frente, no item 1.9 deste trabalho, vai da primeira série do segundo grau até o momento desta entrevista.

O primeiro momento compõe a categoria "sentimentos", formada pelas seguintes representações: sentimentos de segurança, relacionados com a presença da mãe na sala de aula nos primeiros anos escolares, o que lhe possibilitava prestar atenção à aula. A figura da mãe aparece nesta entrevista como uma pessoa de grande significado, revelando sentimentos ambivalentes. Se nos primeiros anos a mãe é uma pessoa que lhe transmite segurança e permite prestar atenção às aulas, em outros momentos é também quem cria obstáculos para a continuação de seus estudos. A mãe surge também associada às situações de brigas, "sermões" e exigências, estando associada, ainda, às indagações sobre sua identidade de retardada ou de preguiçosa que não gosta de estudar: “...quando minha mãe brigava comigo e tinha prova, por mais que eu me esforçava para deixar as brigas para lá e fazer a minha prova, eu não conseguia. Isso não foi esse ano e o ano passado, o caminho todo do colégio foi isso".

Surge também o sentimento de querer ser igual aos outros, em relação aos colegas.

Compõem a categoria "outros" as seguintes representações: 
Os colegas riam muito de mim. Eu queria provar alguma coisa, não para os outros, mas para mim mesma. As pessoas até tinham raiva de falar comigo porque tudo era o colégio. Eu sempre senti um pouco de inveja das minhas amigas que tiravam notas e eu não. Sempre teve alguma diferença entre eu e os meus colegas do primário e do ginásio, as crianças riam de mim e eu não entendia muito por quê. Eu era muito humilhada porque eu não tinha consciência do que eles riam, do que eles gozavam de mim, da minha voz, gozavam do jeito de eu rir. Tinha alguns exercícios físicos que eu não conseguia fazer, e todo mundo ria, eu não entendia aquilo. Tinha épocas que eu não agüentava ir para uma sala de aula. Também tinha uns colegas que tiravam sarro, daí eu só ficava brava, só ficava emburrada, só ficava triste e eu não ouvia mais nada o que o professor explicava. Eu me sentia arrasada de ver todo mundo passando e eu não, eu em recuperação. Eu queria fugir dos meus pais, dos meus colegas, enfim, de todo mundo. (...) Eu queria ser como ela [sua irmã] e, como eu não conseguia, quando eu reprovava era um sentimento... Eu não sei explicar, mas um sentimento ruim, eu me sentia inútil, incapaz, retardada e tudo o que pode imaginar.

A seguir são pontuados outros núcleos de significado que surgiram ao longo dos seus relatos após a idade escolar, com análise e interpretação destes significados.

\subsection{Ansiedade para saber mais sobre si mesma}

$\mathrm{Na} 21^{\mathrm{a}}$ sessão Mara mostra-se bastante nervosa. Começa a chorar e a dizer que não é fácil, que é uma barra, que ninguém a ajuda, que a estagiária sabe que sozinha ela não conseguirá, que não é fácil sentir-se a última do mundo porque é diferente, que havia mudado e que, quanto mais ela quer se libertar, mais se sente presa, que ninguém a entende, por isso sempre me perguntava se estava entendendo; que todo mundo a trata como retardada, que só por um problema do nascimento ela não pode ser normal. Diz que tudo depende do exame neurológico, que para seus pais é muito importante saber se tem alguma coisa.

Em vários momentos de sua fala percebem-se períodos de alternância entre a dependência da mãe e a afirmação do eu: "Tenho medo de crescer". Indica, com isto, que o $e u$ não tomou, ainda, em relação ao outro, estabilidade e independência, que parecem indispensáveis à consciência de si e à constituição da pessoa (Wallon, 1975). A mãe de Mara não dava con- dições para que ela se opusesse em relação ao outro. Qualquer tentativa de oposição para se afirmar era respondida com chantagens, dificultando, assim, a necessária oposição para sua afirmação do $e u$ (Wallon, 1975). Segundo Mara, “...a mãe faz chantagens o tempo todo”. Conta que a mãe fala que ela será assassina caso (a mãe) morra, que a vida toda dedicou a ela, que ela está diferente, que mais uma briga e vai mandá-la para fora de casa. Sentia-se "uma prisioneira": "Eles me deram uma espessura, como um fio, ele vai até um limite e daí eles me puxam. Quando eu quero ir além deste limite eles me puxam”.

Nesta mesma sessão, volta a afirmar que está muito curiosa para saber se é "retardada". E pergunta o que é disritmia, porque sua prima disse que é o que ela tem e que afetou sua coordenação motora.

\subsection{Novas percepções pessoais}

Mara chegou a uma das sessões dizendo que conseguiu alguns progressos, mas sente que precisa mudar muito: "Existem duas Maras brigando dentro de mim: a Mara criança e a Mara adulta". Segundo ela, seus familiares reclamam que ultimamente está "respondona" e não se comporta direito.

A estagiária pergunta qual Mara ela prefere ser, e ela diz que sabe o que gostaria de ser, porém não consegue mudar. Questionada pela estagiária a respeito do que está fazendo para mudar, fala que é difícil, pois não encontra apoio em casa, porque lá todos a tratam como retardada.

Mara retorna animada após as férias porque está trabalhando em uma campanha política, o que considera muito bom enquanto procura outro emprego. Diz que teve que tomar decisões sozinha e conseguiu. Afirma: "A Mara antiga está morrendo e a nova está crescendo. Tenho medo que pequenas coisas me derrubem, mas não um medo pavoroso, é um medo bom. Quando a gente tenta mudar, a gente ganha e perde, $e$ isso dá medo. Tenho medo que você ache que estou bem e me mande embora, tenho medo de mostrar uma Mara segura e depois perder isso". Na outra sessão ela diz: "A gente só pára pra pensar quando tem interesse. A minha identidade é importante para mim".

Comenta que a terapia tem ajudado muito, que ela "cresceu" e acha que precisa continuar porque quer melhorar.

Mara está fazendo tratamento fonoaudiológico duas vezes por semana e acha que isso tem melhorado sua dicção. Está trabalhando há cinco meses como empregada doméstica, ganhando cerca de um terço do salário mínimo. Diz não estar satisfeita, mas tem medo de sair e não conseguir outro emprego. Em outra sessão, afirma: "No fundo eu sou um ser humano normal, não perfeito, normal, com fraquezas". 


\subsection{Novas possibilidades}

Mara continua o tratamento com uma quarta estagiária. Na primeira sessão conta que está estudando à noite, fazendo Educação Geral (segundo grau). Comenta que foi mal numa prova e teve uma crise de choro na sala de aula, mas o professor the deu nova chance, em segredo. Mara pensa que isto é injusto com as colegas. Pergunta-se se tem o direito de estudar, de estar ali. Diz que sua vida não muda, que ela é como um poste de luz, que está ali, chova ou faça sol, e ele não muda. Fala que quer crescer, ter uma identidade. Afirma que não consegue estudar, tem medo e chora. Pergunta a si mesma se é louca e se seu cérebro é realmente "um pouco maior que o de um papagaio, como um neurologista falou".

Mara passa a ser atendida pela quinta estagiária. Chega à primeira sessão pedindo que a estagiária diga para ela o que a sua professora, supervisora do estágio, tem a dizer sobre o seu caso. A estagiária pergunta qual a avaliação que ela própria faz desses quatro anos de tratamento, e Mara responde que sabe que melhorou bastante, mas que ainda está longe de onde quer chegar, ou seja, "ser uma pessoa normal".

No final deste ano, em entrevista sobre sua história na escola, Mara fala: "Mas eu sinto orgulho de mim! Agora eu sei que tenho um nome, agora eu sei que eu tenho uma identidade. Eu não sou a Mara retardada, eu não sou a Mara inteligente, mas eu sou a Mara do meio, que espera um dia chegar à Mara inteligente ou à Mara vitoriosa. Isto é só um engatinhar para um futuro melhor".

Neste ponto surge o segundo momento da entrevista sobre sua história na escola, que compreende o processo de terapia e em que emerge a categoria "identidade" associada à auto-estima positiva: "Eu consegui, eu conquistei, eu venci, eu sinto orgulho, eu comecei a me valorizar. Sabe, eu comecei a me valorizar um pouco mais, a ter certeza que eu tenho um lugar na sociedade... Eu tenho um lugar na sociedade que eu conquistei, que eu fui atrás, que eu consegui".

A categoria "outros" está representada em falas como: "Eu encontrei pessoas que me tratavam de igual para igual, pessoas que me respeitavam como ser humano, onde bateu brincadeiras, mas não brincadeiras estúpidas para humilhar, mas brincadeiras de companheirismo... Eles se aproximaram de mim. Ninguém fazia cara feia, ninguém imitava meu jeito de falar, ninguém tirava sarro de mim. Eles me davam algum valor. (...) vinham meninas... me pedir explicações de matemática ou de história, que eu sempre fui bem. Eles me valorizavam. A turma me valorizava um pouco, os professores também".

Percebe-se que o seu novo autoconceito está relacionado à valorização que recebe por parte dos outros:
"Eu comecei a me valorizar porque eu via que tinha alguém me valorizando também”.

Em face disso, é relevante perguntar: o que ocorreu para que Mara começasse a mudar sua fala?

\section{UMA NOVA NARRATIVA: ALGUMAS HIPÓTESES}

Algumas hipóteses podem ser levantadas sobre as razões das transformações ocorridas na fala de Mara. Tais hipóteses refletem o olhar a partir do referencial teórico deste trabalho. No entanto, compreendemos que este caso possibilita outras análises e interpretações, principalmente sob a ótica da psicanálise de orientação lacaniana, perspectiva que norteou as sessões de terapia e a coleta de dados examinada neste estudo de caso.

A terapia possibilitou uma nova experiência de relacionamento, que rompia com o círculo vicioso do relacionamento com a mãe, a irmã e outras pessoas de sua convivência social. Mara começou a interagir com outras pessoas (as estagiárias de psicologia), que não tinham a expectativa de que ela se comportasse como "retardada".

Seguem-se alguns comentários sobre as transformações que se deram com Mara, advindas do processo de terapia:

- O espaço terapêutico possibilitou que Mara falasse sobre como percebia sua história e refletisse sobre esta.

- Mara começou a sair de casa sozinha, a se tornar mais independente da mãe e das irmãs.

- Mara foi cursar o segundo grau no período da noite e passou a se relacionar com pessoas mais velhas, as quais provavelmente tiveram também suas dificuldades e estavam atrasadas nos estudos. O relacionamento com esses colegas era diferente do relacionamento com as crianças no primeiro grau, as quais muitas vezes são cruéis com aquele que é diferente, e o comportamento divergente é motivo de zombaria.

- Na relação com os colegas adultos, no segundo grau, não aparecem o estigma de retardada e as situações de humilhação, comuns nos primeiros anos escolares. Pelo contrário, Mara afirma sentir-se valorizada e aceita no grupo.

- O progresso no desempenho escolar também ajudou Mara a mudar seu auto-conceito; por sua vez, a mudança do auto-conceito negativo para o positivo influiu na melhora do seu desempenho.

- No período, fez também um curso de serigrafia, quando passou a se relacionar com pessoas mais velhas. Começou a trabalhar fora.

Interação em Psicologia, jul./dez. 2002, (6)2, p. 213-222 


\section{DISCUSSÃO}

Mara é um exemplo dentre o grupo de crianças que têm distúrbios psiconeurológicos de aprendizagem, em que o potencial de aprendizagem é alterado em consequiência de uma disfunção cerebral. Foi uma criança com dificuldade de articulação da fala, causada provavelmente pela anoxia durante o período do parto.

Ficou claro, durante o trabalho com Mara, que ela não é portadora de retardo mental. O seu desempenho nos testes a insere dentro da média. Sua capacidade de operar com metáforas e conceitos, bem como a reflexão que faz sobre sua condição, não sugerem retardo.

Fatores como sua dificuldade de articulação da fala, associados ao lugar e ao papel que ocupou na família - o de uma criança incapaz, que precisava ser protegida - são elementos que determinaram sua identidade. $\mathrm{O}$ estigma de retardada, colocado na hora do nascimento e recolocado ao longo de seu desenvolvimento pelas pessoas que mediavam sua relação com o mundo, levou-a à construção de um autoconceito de incapacidade para aprender.

Diante da repetição crônica do fracasso escolar, devido a pequenas dificuldades neurofuncionais, passou a apresentar problemas emocionais que resultaram no agravamento psicológico das condições necessárias à aprendizagem.

Em vários momentos reforça-se que Mara é "retardada". A expectativa de que ela se comporte como tal está presente na família e na escola. A dificuldade na articulação da fala, muito valorizada na nossa sociedade, propicia condições favoráveis para que o estigma do retardo seja reposto sucessivamente.

Uma disfunção neurofuncional criou certas limitações para o desenvolvimento de Mara. Porém, fica evidente que as limitações mediadas pelos fatores sociais e psicológicos são as principais limitações na conformação de seu perfil particular; de uma Mara que questiona se é ou não "retardada", de uma Mara com "dificuldade em aprender".

Foram as limitações impostas pelos "outros" que construíram sua identidade particular. A fala dos "outros" está repleta de significados suficientes para conformar sua identidade. Na história do seu desenvolvimento estão presentes, em vários momentos, as afirmações e reafirmações de quem ela era para os "outros".

São os significados contidos nessas afirmações que compõem o conteúdo das indagações que Mara faz agora para si própria. São essas afirmações que voltam, em vários momentos, durante as dúvidas sobre sua identidade de "ser ou não normal". A fala que os outros empregaram com relação a ela soa como eco na fala interna que aplicava sobre si mesma. Mara relacio- nava-se consigo mesma do mesmo modo que as pessoas se relacionavam com ela.

Segundo Vygotsky (1989, p. 143): “...a personalidade converte-se para si naquilo que é em si através do que representa para os outros. Este é o processo de formação da personalidade".

Mara interiorizou os conteúdos, as interjeições, o dito e o não-dito referidos a ela pelas pessoas com as quais estabeleceu relações ao longo do seu desenvolvimento. Citando, ainda, Vygotsky (1989, p. 143): "...foi para os outros o que agora é para si".

No entanto, na passagem do exterior ao interior, esses significados sobre Mara empregados pelos outros sofreram transformações. Não se trata de uma interiorização passiva. As emoções e a vontade de Mara cumpriram o papel de forças motoras para a superação de suas dificuldades. Aqui, ressalta-se o papel da emoção e da vontade na construção do sujeito.

Apesar de todas as condições adversas, com as pessoas afirmando que ela era diferente dos outros, Mara construiu imagens e fantasias que expressavam seu sentimento de não-aceitação desta identidade imposta. A vontade de ser igual às pessoas "normais" e o sentimento de inferioridade transformaram-se em força motriz na luta pela superação e compensação de suas dificuldades. As condições sociais impostas a Mara, as reflexões sobre estas condições e o desejo de superação se converteram em elementos integradores do processo de busca de integridade do $e u$.

As idas e vindas de Mara na afirmação do $e u$, na sua luta em busca da integridade do $e u$ ficam evidentes em sua fala: "Quando eu consigo dar dois passos para a frente dou três para trás; as pessoas normais não fazem isso". Pensa um pouco e diz: "É, talvez as pessoas normais não sejam tão normais".

Mara vai conquistando a independência em relação ao "outro imposto" através das falas referentes a si e internalizadas como dadas para si. "Agora eu sei que tenho um nome, agora eu sei que eu tenho uma identidade. Eu não sou a Mara retardada, eu não sou a Mara inteligente, mas eu sou a Mara do meio, que espera um dia chegar à Mara inteligente ou à Mara vitoriosa. Isso é só um engatinhar para um futuro melhor".

Ela chega à afirmação de sua identidade resumindo e expulsando o "outro" posto e reposto. Mas, como escreve Wallon (1975):

O socius ou o outro é um parceiro perpétuo do eu na vida psíquica. É normalmente reduzido, inaparente, contido e como que negado pela vontade de dominação e de integridade completa do eu. No entanto, toda a deliberação, toda 
a indecisão é um diálogo às vezes mais ou menos explícito entre o eu e um objectante (Wallon, 1975, p. 159).

\section{CONSIDERAÇÕES FINAIS}

O estudo mostrou que são as limitações secundárias, mediadas social e psicologicamente, as que constroem a identidade particular do aluno com dificuldade. Identificou-se, neste estudo de caso, uma classe de emoções e sentimentos que acompanham o desenvolvimento da atividade escolar quando a pessoa tem uma representação de si mesma como incapaz.

A criança com dificuldade de aprendizagem pode apresentar funções pouco desenvolvidas, assim como as crianças com bom desempenho escolar podem apresentar a dominância de uma função sobre a outra. A dificuldade depende essencialmente do lugar que essas funções pouco desenvolvidas ocupam no sistema geral dos processos superiores e também do peso socialmente atribuído a uma determinada função. A mediação social, o papel do outro na representação de si e na formação de sua identidade é que irá ter conseqüências no seu desenvolvimento global. Os sentimentos psicológicos de dificuldade estabelecem condições desfavoráveis para a aprendizagem e, conseqüentemente, para o desenvolvimento (Kozulin, 1994).

Conclui-se, assim, que o diagnóstico e o tratamento das dificuldades de aprendizagem não podem ser reduzidos a problemas médicos e neurológicos. Os estudos neurológicos tratam as dificuldades de aprendizagem como disfunções neurológicas, centrando-se, portanto, nos planos biológico e natural, mas não no histórico. E para o indivíduo, na sua unidade, o que é essencial, decisivo e determinante não são as causas biológicas; os significados atribuídos no sistema de relações sociais é que são os determinantes do seu sofrimento e exclusão.

Este estudo de caso procurou demonstrar que as dificuldades de aprendizagem são desafios pedagógicos que trazem à tona questões que merecem ser tratadas no âmbito das discussões e pesquisas sobre ensino e aprendizagem nos contextos da família, da escola e da sociedade, com o objetivo de desnaturalizar as "dificuldades de aprendizagem".

\section{REFERÊNCIAS}

Anastopoulos, A. D. (1999). Facilitando a compreensão e o manejo do transtorno de déficit de atenção/hiperatividade por parte dos pais. Em M. A. Reinecke; F. M. Dattilio \& A. Freeman. (Orgs.), Terapia cognitiva com crianças e adolescentes (p. 249-260). Porto Alegre: Artes Médicas.

Camargo, D. (1997). As emoções no processo de aprendizagem. Tese de Doutorado - PUC-SP. São Paulo.
Ciampa, A. C. (1986). Identidade. Em S. L. Lane \& W. Codo (Orgs.), Psicologia social: o homem em movimento (p. 58-75). São Paulo: Brasiliense.

Ciampa, A. C. (1987). A estória do Severino e a história da Severina. São Paulo: Brasiliense.

Coll, C.; Palácios, J. \& Marchesi, Á. (1995). Desenvolvimento psicológico e educação. Porto Alegre: Artes Médicas.

Foucault, M. (1979). Microfísica do poder. Rio de Janeiro: Graal.

Garcia, J. N. (1998). Manual de dificuldade de aprendizagem. Porto Alegre: Artes Médicas.

Grégoire, J. \& Piérart B. (1997). Avaliação dos problemas de leitura. (M. R. B. Osório, trad.). Porto Alegre: Artes Médicas.

Grégoire, J. \& Piérart B. (2000). Avaliando as aprendizagens: os aportes da psicologia cognitiva. (C. M. Bruno, trad.). Porto Alegre: Artes Médicas.

Kleiman, Â. (2001). A construção da identidade em sala de aula: um enfoque interacional. Em I. Signorini (Org.), Língua(gem) e identidade (p. 267-302). Campinas: Mercado de Letras.

Kozulin, A. (1994). La psicologia de Vygotsky. Madrid: Alianza Editorial.

Lane, S. M. (1989). Análise gráfica do discurso. Mimeografado. São Paulo: PUC.

Marchesi, Á. \& Martín, E. (1995). Da terminologia do distúrbio às necessidades educacionais especiais. Em C. Coll; J. Palacios \& Á. Marchesi (Orgs.), Desenvolvimento psicológico e educação (p. 7-23). Porto Alegre: Artes Médicas.

Rosenthal, R. \& Jacobson, L. (1998). Profecias auto-realizadoras em sala de aula: as expectativas dos professores como determinantes não intencionais da competência intelectual. Em M. H. Souza Patto (Org.), Introdução à psicologia escolar (p. 258-295). São Paulo: T. A. Queiroz Editor.

Rourke, B. P. (1985). Neuropsychology of learning disabilities: essentials of subtype analysis. New York: Guilford Press.

Scoz, B. J.; Rubsinstein, E.; Rossa, E. M. \& Barone, L. M. (1987). Psicopedagogia: o caráter interdisciplinar na formação e atuação profissional. Porto Alegre: Artes Médicas.

Smith, C. \& Strick, L. (2001). Dificuldades de aprendizagem de A a Z Porto Alegre: Artmed.

Smolka, A. L. B. (1991). A prática discursiva na sala de aula: uma perspectiva teórica e um esboço de análise. Cadernos CEDES 24, 51-65. Pensamento e Linguagem. São Paulo: Papirus.

Souza Patto, M. H. (1989). Introdução à psicologia escolar. São Paulo: T. A. Queiroz.

Trapani, C. \& Gettinger, M. (1999). Tratamento de alunos com transtornos de aprendizagem. Em M. A. Reinecke; F. M. Dattilio \& A. Freeman (Orgs.), Terapia cognitiva com crianças e adolescentes (p. 197-214). Porto Alegre: Artes Médicas.

Vygotsky, L. S. (1993). Obras Escogidas II. Madrid: Visor Distribuiciones.

Vygotsky, L. S. (1989). Historia del desarrollo de las funciones psíquicas superiores. Em Vygotsky; Leontiev \& 
Luria (1989). El proceso de formación de la psicología marxista. Moscou: Editorial Progresso.

Wallon, H. (1975). Psicologia e educação da infância. Lisboa: Editorial Estampa.

Recebido: 09.10.2002

Revisado: 06.11.2002

Aceito: 22.11.2002

\section{Notas:}

${ }^{1}$ Smith \& Strik (2001) usam o termo dificuldade de aprendizagem (learning disabilities) não para um único distúrbio, mas para uma ampla gama de problemas que podem afetar qualquer área do desempenho acadêmico.

${ }^{2}$ Identidade compreendida dentro do referencial do trabalho de Antonio Ciampa (1986 e 1987) como construção, num infindável processo de transformação. Identidade como movimento onde o contexto histórico e social em que o homem vive marca sua determinação e, conseqüentemente, emergem as possibilidades ou impossibilidades, os modos e as alternativas de sermos o Eu e um Outro.

${ }^{3}$ A emoção é entendida como função motivacional maior concebida como reação de um sistema orgânico total, com componentes de representação, de expressão e motórico-fisiológicos. Como todas as funções humanas, é preciso pensá-la histórica e culturalmente situada. O termo sentimento é empregado no sentido de que, nele, a expressão motórico-fisiológica é menos declarada que a expressão que ocorre na emoção (Camargo, 1997).

4 "Núcleos de significação" ou "núcleo de significado" fundamenta-se na concepção de que o discurso, produto da interação entre pensamento e linguagem, se processa em espiral, havendo assim, retornos e avanços, semelhanças e diferenciações. Este movimento em espiral caracteriza significações centrais e periféricas que vamos procurar na fala do entrevistado identificando núcleos de significação. (Vygotsky, 1993; Lane, 1989).

${ }^{5}$ Entrevista aberta visando a possibilitar o discurso livre e suas interligações. A pesquisadora pede para que Mara conte como foi sua história na escola. A entrevista foi gravada e transcrita para permitir a análise gráfica.

${ }^{6}$ A análise da entrevista foi feita utilizando-se a técnica de Análise Gráfica do Discurso, criada por Silvia M. Lane (1989).

${ }^{7}$ Não tivemos acesso aos resultados dos exames neurológicos. Os testes aplicados foram a Bateria CEPA e o teste CIA de inteligência. O resultado da bateria situou Mara superior à média na aptidão para resolver problema, principalmente no plano lógico abstrato, o que revela, segundo o manual do teste, um bom poder de previsão e planejamento e uma boa compreensão verbal de raciocínio indutivo e dedutivo. Em aptidão mnemônica visual situou-se superior à média, o que indica facilidade de memorização visual. $\mathrm{O}$ teste indicou que Mara apresentou dificuldade em linguagem, tanto na rapidez como na facilidade de expressão verbal. Apresentou dificuldade para a compreensão da linguagem, principalmente no que se refere à exatidão e a compreensão de idéias expressas verbalmente. Mostrou-se inferior à média em aptidão mnemônica auditiva e relações espaciais. Demonstrou dificuldade em utilizar, exata e rapidamente, símbolos numéricos.

No teste CIA de inteligência, situou-se na média em capacidade de compreender e apreciar uma situação total e na capacidade de classificar e conceituar, o que, segundo o teste, indica grau de maturidade normal. A habilidade de análise e síntese e sua capacidade associativa se encontram também dentro dos padrões de normalidade. Apresentou rendimento médio quanto à posse de informações práticas e na amplitude do conhecimento geral e também na capacidade de perceber e diferenciar detalhes essenciais e acidentais. E o raciocínio aritmético situou-se um pouco inferior à média, o que revela dificuldades nesse aspecto. Seu quociente de inteligência global situou-se dentro dos padrões normais, sendo que seu desempenho não-verbal é um pouco melhor do que o verbal.

\section{Sobre a autora}

Denise de Camargo: Doutora em Psicologia Social pela Pontifícia Universidade Católica de São Paulo. Professora do Mestrado em Psicologia da Infância e Adolescência, da Universidade Federal do Paraná. Endereço para correspondência: Rua Raposo Tavares, 5.332. São João. Curitiba, PR CEP:82.100-000. Fone: (0xx41) 338-2175. E-mail: denisedecamargo@uol.com.br 